\title{
Improvements in the reactor core isolation cooling (RCIC) pump model
}

\author{
Hongbin Zhang
}

James O'Brien

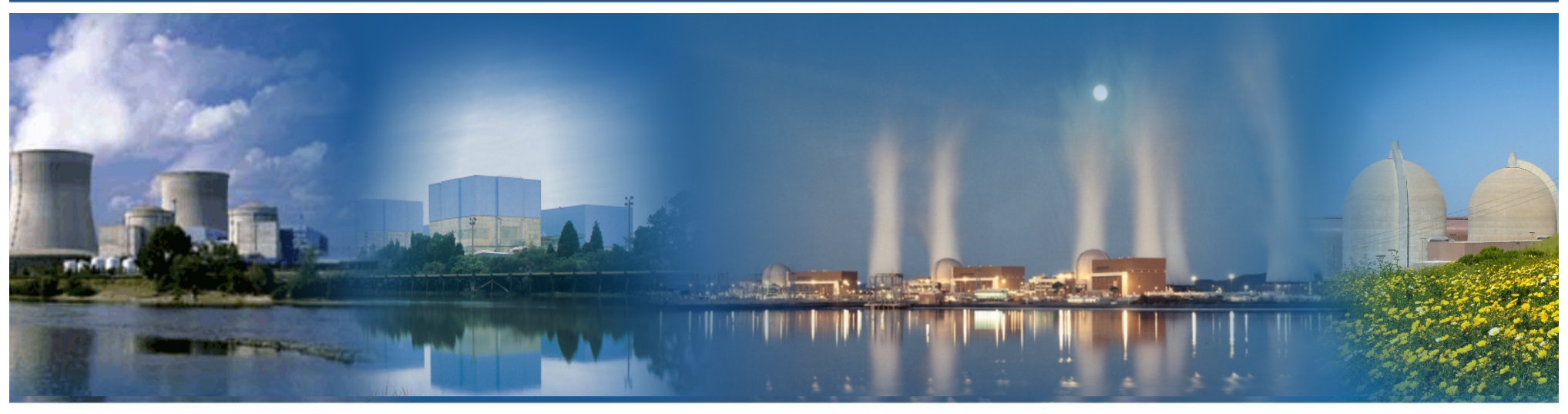

February 2018 


\section{DISCLAIMER}

This information was prepared as an account of work sponsored by an agency of the U.S. Government. Neither the U.S. Government nor any agency thereof, nor any of their employees, makes any warranty, expressed or implied, or assumes any legal liability or responsibility for the accuracy, completeness, or usefulness, of any information, apparatus, product, or process disclosed, or represents that its use would not infringe privately owned rights. References herein to any specific commercial product, process, or service by trade name, trade mark, manufacturer, or otherwise, does not necessarily constitute or imply its endorsement, recommendation, or favoring by the U.S. Government or any agency thereof. The views and opinions of authors expressed herein do not necessarily state or reflect those of the U.S. Government or any agency thereof. 
Improvements in the reactor core isolation cooling (RCIC) pump model

Hongbin Zhang, James O'Brien

February 2018

Idaho National Laboratory Idaho Falls, Idaho 83415

http://www.inl.gov

Prepared for the U.S. Department of Energy Office of Nuclear Energy Under DOE Idaho Operations Office

Contract DE-AC07-05ID14517 


\section{EXECUTIVE SUMMARY}

As part of the efforts to understand the unexpected "self-regulating" mode of the RCIC (Reactor Core Isolation Cooling) systems that was observed during the Fukushima accidents and to extend BWR RCIC and PWR AFW (Auxiliary Feed Water) operational range and flexibility, mechanistic models for the Terry turbine are being developed and tested with the RELAP-7 code to simulate the RCIC system. In the previous work, we developed a set of analytical models for the normal working conditions, as well as the two-phase off-design conditions, of the RCIC system, based on Sandia's original work. An under-expanded jet model was developed to replace the CFD-based reduced-order model in the Sandia work to obtain the velocity and thermodynamic conditions of the turbine stator inlet. The models include both an adiabatic expansion process inside the nozzle and a free expansion process outside of the nozzle to ambient pressure. For the two-phase off-design conditions, two well-established choking models were used - the Isentropic Homogenous Equilibrium Model (IHEM) and Moody's model. The new twophase Terry turbine model used the choking models to calculate the mass flow rate, the critical pressure at the nozzle throat, and steam quality. The two-phase nozzle expansion model was also developed by considering the vapor phase with a similar model for the single-phase case with the assumption that the liquid phase would slip along the wall with a much slower speed and will not contribute to the impulse on the rotor.

A RCIC Pump model was also developed and implemented into the RELAP-7 code to couple with the Terry turbine model. It was discovered during this study that the RCIC Pump model is under-constrained, resulting in non-unique solutions of the pump temperature. This work presents an Improved RCIC Pump model to remedy the underconstrained equation set. The pump homologous curves are also implemented into the Improved RCIC Pump model.

The Improved RCIC Pump model along with the Homologous Curves, the singlephase and two-phase nozzle models and the modified turbine rotor model according to the original Sandia work were tested with the RELAP-7 code, along with the original Sandia Terry turbine model. An input model was developed to test the Terry turbine RCIC system, with reasonable results generated. The Improved RCIC Pump model along with the Homologous Curves were further tested with a RCIC system test case to simulate the self-regulated Terry turbine behavior observed in Fukushima accidents. In this test, a periodic inlet condition for the steam quality varying from 1 to 0.1 is applied. For the high-quality inlet period, the RCIC system behaves just like the normal operation condition with a high pump injection flow rate and a nominal steam release rate through the turbine; for the low-quality inlet period, the RCIC turbine shaft work decreases and results in a much reduced pump injection flow rate, and the mixture flow rate through the turbine increases due to the high liquid-phase flow rate.

The work discussed in this report represents the first preliminary models for simulating RCIC system off-design conditions. Many other two-phase model options can be considered. The near future work should be focused on using Terry turbine test data to validate the proposed models when the data become available. Additional model refinement will also be pursued, such as trying other choking models and investigating different expansion models in the nozzle divergent section, and developing thermal mixing and stratification models for the wet well. 


\section{ACKNOWLEDGEMENTS}

The funding for this project is provided by the Reactor Safety Technology Pathway of the Light Water Sustainability Program, U.S. Department of Energy. 


\section{CONTENTS}

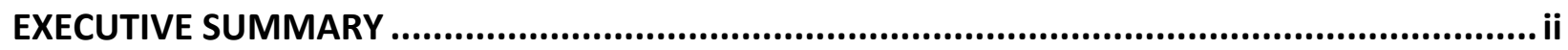

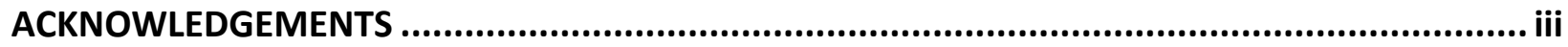

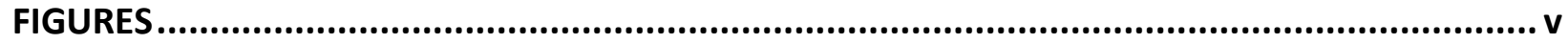

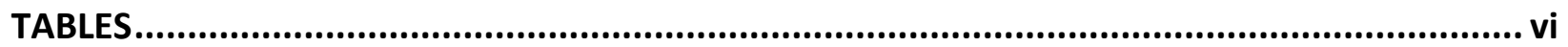

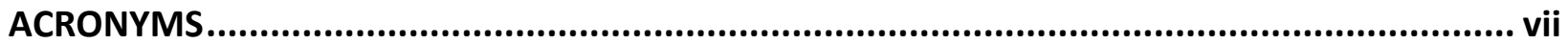

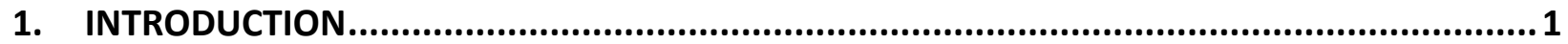

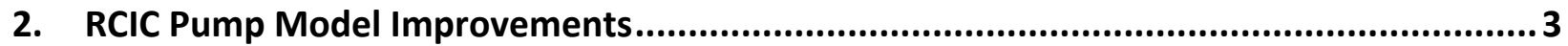

2.1 Summary of the Previously Developed INL's Terry Turbine Rotor Model and Pump Model......3

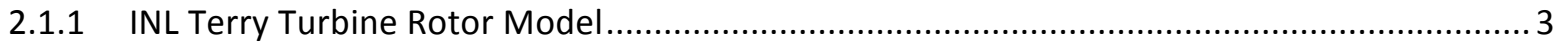

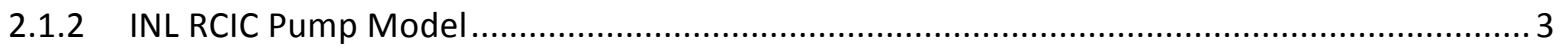

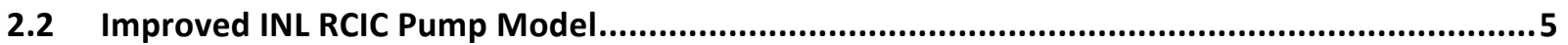

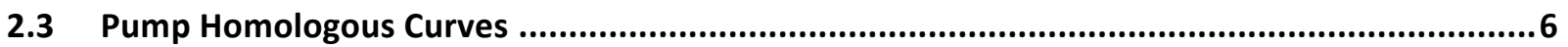

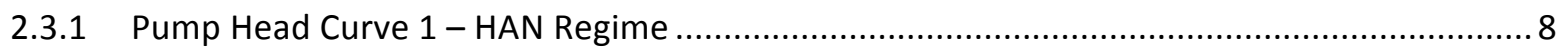

2.3.2 Pump Head Curve 2 - HVN Regime ........................................................................ 8

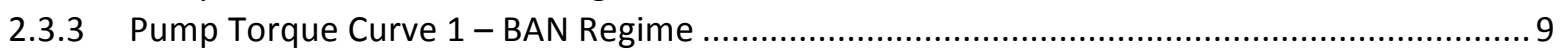

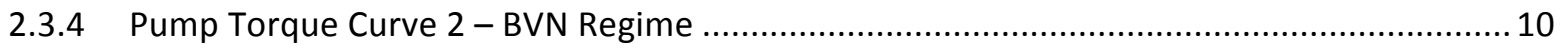

2.4 Summary of Improved RCIC Pump Model with Homologous Curves ......................................11

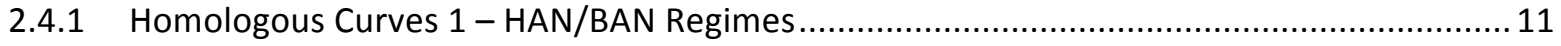

2.4.2 Homologous Curves 2 - HVN/BVN Regimes ............................................................... 11

3. IMPROVED RCIC PUMP MODEL WITH HOMOLOGOUS CURVES TESTS.......................... 13

3.1 Improved RCIC Pump Model Start-up Tests with Homologous Curves ...................................13

3.2 RCIC System Test with Periodic Inlet Boundary Conditions ..................................................16

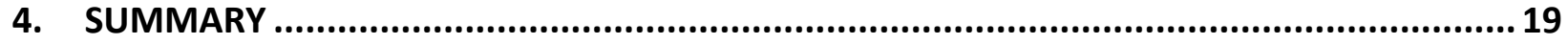

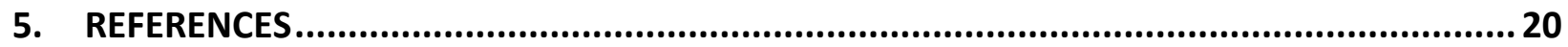




\section{FIGURES}

Figure 1. Terry turbine bucket flow (left) and interior view of turbine case (right) [1] .......................... 1

Figure 2. RELAP-7 Terry turbine RCIC system test model................................................................. 13

Figure 3. Specified turbine inlet steam quality for the RCIC system simulation with periodic inlet condition

Figure 4. Calculated mass flow rates through the RCIC - mixture and steam through the turbine nozzle exit, water through the pump for the RCIC system simulation with periodic inlet condition with the Moody model.

Figure 5. Calculated RCIC pump efficiency for the RCIC system simulation with periodic inlet condition with the Moody model. 


\section{TABLES}

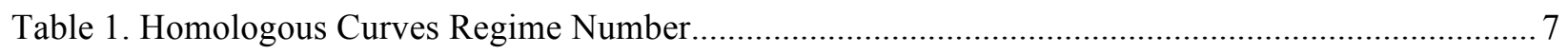

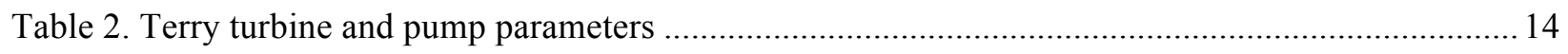

Table 3. Important Terry turbine and pump calculated parameters at steady state for outlet pressure at 193

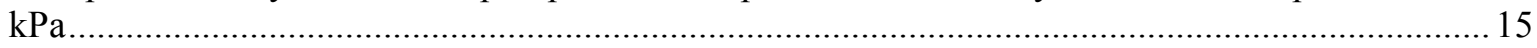

Table 4. Important Terry turbine and pump calculated parameters at steady state for outlet pressure at 300

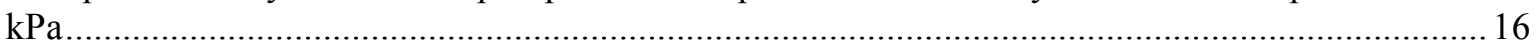




\section{ACRONYMS}

$\begin{array}{ll}\text { 0-D } & \text { zero-dimensional } \\ \text { AFW } & \text { Auxiliary Feed Water } \\ \text { BC } & \text { Boundary Condition } \\ \text { BWR } & \text { Boiling Water Reactor } \\ \text { CFD } & \text { Computational Fluid Dynamics } \\ \text { FY } & \text { Fiscal Year } \\ \text { IHEM } & \text { Isentropic Homogeneous Equilibrium Model } \\ \text { INL } & \text { Idaho National Laboratory } \\ \text { LWRS } & \text { Light Water Reactor Sustainability } \\ \text { RCIC } & \text { Reactor Core Isolation Cooling } \\ \text { RELAP-7 } & \text { Reactor Excursion and Leak Analysis Program 7 } \\ \text { PWR } & \text { Pressurized Water Reactor } \\ \text { SBO } & \text { Station Blackout } \\ \text { SRV } & \text { Safety Relief Valve }\end{array}$




\section{INTRODUCTION}

As part of the efforts to understand the unexpected "self-regulating" mode of the RCIC (Reactor Core Isolation Cooling) systems in Fukushima accidents and extend BWR RCIC and PWR AFW (Auxiliary Feed Water) operational range and flexibility, mechanistic models for the Terry turbine, are being developed and tested with the RELAP-7 code to simulate the RCIC system. All BWR RCIC systems and PWR AFW systems use Terry turbines. The Terry turbine, as shown in Figure 1, is essentially a solid cylindrical wheel with multiple machined semi-circular 'buckets' that are shaped into the body of the wheel. Fixed nozzles and reversing chambers surrounding the wheel are inside the turbine casing. High pressure steam is accelerated to supersonic flow inside the turbine nozzle. The steam kinetic energy is then converted to shaft work by the impulse force on the turbine buckets.

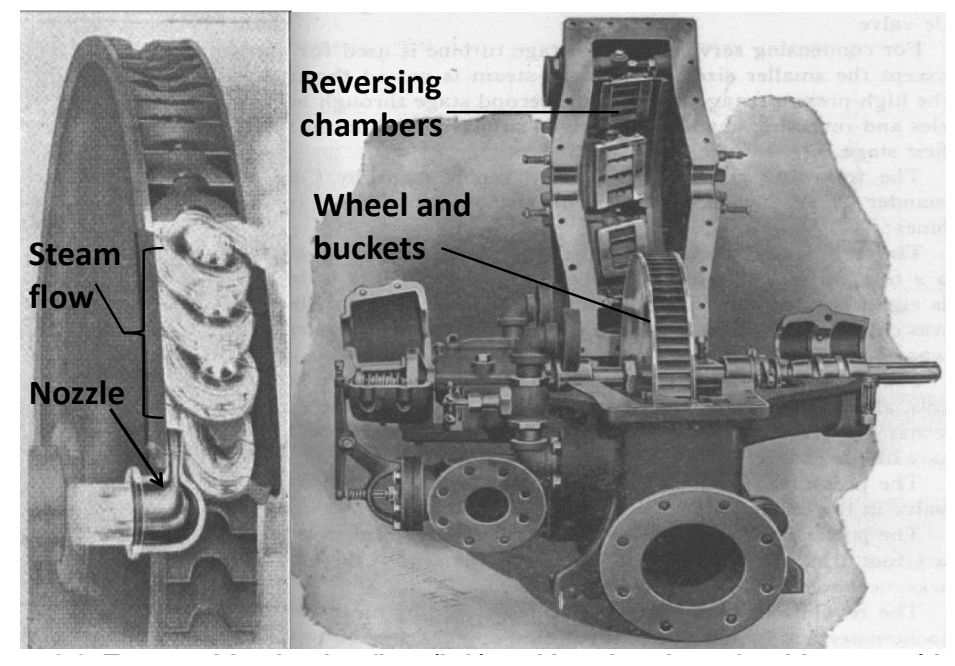

Figure 1. Terry turbine bucket flow (left) and interior view of turbine case (right) [1]

Prior to the Fukushima accidents, all the safety analyses assumed that the RCIC system couldn't work properly if the Terry turbine inlet is flooded. Under the normal operating condition, the water mass flow rate through the turbine-driven pump into the primary system is about 10 times the steam mass flow rate through the Terry turbine leaving the primary system. Therefore, battery power (can last from 4 to 12 hours) is required to control the RCIC system in order to prevent the reactor vessel water level from rising too high; otherwise loss of DC power would result in flooding of the steam lines and an assumed subsequent failure of the RCIC system [1 and 2]. In contrast, real-world observation from Fukushima Daiichi Unit 2 (1F2) shows that RCIC function was not terminated by loss of DC power and uncontrolled steam line flooding, and instead continued providing water injection for nearly three days.

A set of Terry turbine models suitable for system code implementation was developed by Sandia National Labs in FY15 [1]. The Sandia Terry turbine model is based on the following assumptions:

- RCIC uses a single-stage Terry impulse turbine that functions according to the exchange of momentum and kinetic energy.

- Steam enters semi-circular buckets and reverses direction $\left(\sim 180^{\circ}\right)$.

- The reversing chambers are only important for low-speed operation, such as during the initial startup. 
- The expansion of steam downstream of the nozzles is total; the expansion process converts the static pressure (enthalpy energy) of the steam into kinetic energy to be imparted into the turbine buckets. No meaningful reaction force is developed by the Terry turbine.

The Sandia Terry turbine model is composed of a turbine nozzle model and a turbine rotor model. For the Sandia turbine nozzle model, the turbine bucket inlet velocity is provided according to a reduced-order model which was obtained from a large number of CFD simulations. This reduced-order model is only valid for the specific nozzle design and operating conditions for which the CFD simulations were performed.

In our previous work, we developed a set of analytical models [4] for the normal working conditions of the RCIC system, based on Sandia's original work [1]. In this new set of models, we proposed an alternative method, using an under-expanded jet model to replace the CFD-based reduced-order model in the Sandia work to obtain the velocity and thermodynamic conditions for the turbine stator inlet. The models include both an adiabatic expansion process inside the nozzle and a free expansion process outside of the nozzle to ambient pressure. The newly developed nozzle models and the modified turbine rotor model according to the Sandia's original work were tested with RELAP-7, along with the original Sandia Terry turbine model. A new pump model was also developed and implemented to couple with the Terry turbine model. For brevity, we refer to the set of RELAP-7 RCIC models as INL RCIC model or INL model, which is composed of two parts:

- Nozzle model which predicts mass flow rate through the turbine and inlet conditions for the rotor (semi-circular buckets),

- Turbine rotor model which describes the balance of angular momentum of the wheel.

The INL model is able to predict the steam mass flow rate and supersonic velocity at the Terry turbine bucket entrance, which are the necessary input conditions for the Terry Turbine rotor model. The nozzle analytical models were validated with experimental data and benchmarked with CFD simulations. The analytical models generally agree well with the experimental data and CFD simulations.

The INL single-phase analytical Terry turbine model was later extended to cover two-phase off-design conditions [5]. The work included: (1) adding well-established two phase choking models - Isentropic Homogenous Equilibrium Model (IHEM) and Moody's model, and (2) theoretical development and implementation of a two-phase nozzle expansion model.

A new pump model was also developed and implemented into the RELAP-7 code to couple with the Terry turbine model $[4,5]$. All the models were tested with the RELAP-7 system analysis code and input models were also developed for benchmark, validation, and tests. However, it was discovered during the subsequent testing that the new pump model is under-constrained, resulting in non-unique solutions of the pump temperature. Consequently, an improved INL RCIC pump model had to be developed.

This report presents the effort to: 1) improve the INL RCIC pump model, and 2) implement homologous curves. Section 2 discusses the improvement of the pump model and the implementation of the homologous curve. Section 3 presents a test of the improved RCIC pump model. Section 4 summarizes the work. 


\section{RCIC Pump Model Improvements}

\subsection{Summary of the Previously Developed INL Terry Turbine Rotor Model and Pump Model}

\subsubsection{INL Terry Turbine Rotor Model}

As reported in our previous work [5], the Terry turbine rotor model developed by Sandia [1] has been adopted with only one modification for consideration of the angular momentum conversion efficiency. The angular momentum relationship on the turbine wheel control volume is used for the turbine rotational speed $(\omega)$ :

$$
I \frac{d \omega}{d t}+\frac{\tau_{\text {pump }}}{1+\cos \beta}=c_{I C}\left(2 r \dot{m} V_{j} \frac{\cos \beta}{1+\cos \beta}-r^{2} \dot{m} \omega\right)
$$

In Eq. (1), $I$ is the turbine moment of inertia. $\tau_{\text {pump }}$ is the pump torque, which will be coupled from a pump model. $\beta$ is the inlet/exit angle between the fluid velocity vectors and the horizontal/tangential direction of the turbine motion. $C_{I C}$ is an impulse conversion coefficient to account for the efficiency to convert the fluid kinetic energy to the driving moment for the angular momentum. This is a new concept added to the original Sandia model. A coefficient model should be developed according to experimental results. $\dot{m}$ is the mass flow rate. $V_{j}$ is the nozzle jet velocity as calculated by the virtual nozzle exit velocity model.

The turbine shaft work supplied to the pump is calculated as

$$
\dot{W}_{t}=\tau_{\text {pump }} \omega
$$

\subsubsection{INL RCIC Pump Model}

The pump model for the RCIC system is based on two assumptions:

- quasi-steady state,

- incompressible flow,

We designed the pump as one 0 -D junction component which provides:

- one BC for upstream pipe: pressure

- two BCs for downstream pipe: pressure and total energy.

Four scalar variables: pump pressure $p_{J}$, pump temperature $T_{J}$, pump head $H$, and pump torque $\tau_{\text {pump }}$ are defined as the unknowns for the pump model.

The pump pressure unknown corresponds to the mass balance as the nonlinear equation:

$$
(\rho u A)_{1}-(\rho u A)_{2}=0
$$

where subscript 1 and 2 indicate inlet and outlet conditions.

The pump temperature corresponds to the pump energy conservation equation: 


$$
\left(E+\frac{p}{\rho}\right)_{2}(\rho u A)_{2}=\left(E+\frac{p}{\rho}\right)_{1}(\rho u A)_{1}+\left(1-\eta_{p}\right) \dot{W}_{t}
$$

where the total energy is defined as

$$
E=e+\frac{1}{2} u^{2}
$$

and e is the specific internal energy. In Eq. (4), $\eta_{p}$ is the pump efficiency.

The pump head $H$ is calculated as

$$
H=\frac{\eta_{p} \dot{W}_{t}}{(\rho u A)_{1} g}
$$

where $g$ is the gravitational constant.

The pump torque is calculated according to a scaling law as used in the Sandia model:

$$
\tau_{p u m p}=\frac{\tau_{p 0}}{\omega_{0}^{2}} \omega^{2}
$$

where $\tau_{p 0}$ and $\omega_{0}$ are the rated pump torque and speed, respectively.

Pressures at the pump inlet and outlet are calculated with the incompressible flow Bernoulli equation. We assume that the pump work is added to the fluid only in the entrance segment and the loss in the exit segment is ignored. For normal flow

$$
\begin{gathered}
p_{1}=\left(p_{J}+\frac{1}{2} \rho_{J} u_{J}^{2}\right)-\rho_{1} g H-\frac{1}{2} \rho_{1} u_{1}^{2} \\
p_{2}=\left(p_{J}+\frac{1}{2} \rho_{J} u_{J}^{2}\right)-\frac{1}{2} \rho_{2} u_{2}^{2}
\end{gathered}
$$

where

$$
\begin{gathered}
\rho_{J}=\rho\left(p_{J}, T_{J}\right) \\
u_{J}=\frac{(\rho u A)_{1}}{\rho_{J} A_{J}}
\end{gathered}
$$

where $A_{J}$ is the pump reference cross section area.

Downstream total energy is calculated by

$$
(\rho E)_{2}=\rho_{2}\left(e\left(p_{J}, T_{J}\right)+\frac{1}{2} u_{2}^{2}\right)
$$

It has been discovered during the subsequent testing that the aforementioned previously developed turbine-driven pump model does not provide strong enough constraints, which results in un-defined temperature solutions for the pump. The pump temperature would float erroneously during the iterations to find solutions of the unknown variables. Consequently, the mass conservation and energy conservation equation (Eqs. (3) and (4)) have to be modified to provide appropriate constraints to the equation set such that unique solutions of the unknowns can be found. An alternative model for the conservation equations has been developed and implemented into the RELAP-7 code. The improved model is described in subsection 2.2. 


\subsection{Improved INL RCIC Pump Model}

The angular momentum relationship on the turbine wheel control volume remains unchanged:

$$
I \frac{d \omega}{d t}+\frac{\tau_{\text {pump }}}{1+\cos \beta}=c_{I C}\left(2 r \dot{m} V_{j} \frac{\cos \beta}{1+\cos \beta}-r^{2} \dot{m} \omega\right)
$$

The turbine shaft work supplied to the pump is calculated as:

$$
\dot{W}_{t}=\tau_{\text {pump }} \omega
$$

The mass and energy conservation equations are modified to add the rate of change in time for the density and energy terms respectively. These additions make the RCIC pump model appropriately constrained as well as to make the code more robust to handle the transition from startup to normal operating conditions.

The pump mass balance equation is:

$$
V \frac{\partial \rho}{\partial t}=(\rho u A)_{1}-(\rho u A)_{2}
$$

where $\mathrm{V}$ is the volume of the fluid inside the pump, subscripts 1 and 2 indicate inlet and outlet conditions. The primary variable for this equation is the density $\rho$.

The pump energy conservation equation is:

$$
V \frac{\partial(\rho e)}{\partial t}=\left(E+\frac{p}{\rho}\right)_{1}(\rho u A)_{1}+\dot{W}_{t}-\left(E+\frac{p}{\rho}\right)_{2}(\rho u A)_{2}
$$

where the total energy is defined as

$$
E=e+\frac{1}{2} u^{2}
$$

and e is the specific internal energy. The primary variable for this equation is $\rho e$ which is used to approximate $\rho E$. Since the RELAP-7 code obtains the solutions through residual reduction, re-writing Eq. (16) in the residual form yields:

$$
R e s=-V \frac{\partial(\rho e)}{\partial t}+(\rho E A+P A)_{1} u_{1}+\dot{W}_{t}-(\rho E A+P A)_{2} u_{2}
$$

The Jacobians are the following:

$$
\begin{gathered}
\text { kee }(0,0)=\frac{\partial R e s}{\partial(\rho e)}=-\mathrm{V} \frac{\partial(\rho e) / \partial t}{\partial(\rho e)} \\
\frac{\partial R e s}{\partial(\rho A)_{1}}=-u_{1}\left(\frac{(\rho E A+P A)_{1}}{(\rho A)_{1}}+\frac{\partial P}{\partial \rho_{1}}\right) \\
\frac{\partial \operatorname{Res}}{\partial(\rho u A)_{1}}=\frac{(\rho E A+P A)_{1}}{(\rho A)_{1}}+\frac{\partial P}{\partial(\rho u)_{1}} u_{1} \\
\frac{\partial \operatorname{Res}}{\partial(\rho E A)_{1}}=u_{1}\left(1+\frac{\partial P}{\partial(\rho E)_{1}}\right) \\
\frac{\partial \operatorname{Res}}{\partial(\rho A)_{2}}=-u_{2}\left(\frac{(\rho E A+P A)_{2}}{(\rho A)_{2}}+\frac{\partial P}{\partial \rho_{2}}\right)
\end{gathered}
$$




$$
\begin{gathered}
\frac{\partial R e s}{\partial(\rho u A)_{2}}=\frac{(\rho E A+P A)_{2}}{(\rho A)_{2}}+\frac{\partial P}{\partial(\rho u)_{2}} u_{2} \\
\frac{\partial R e s}{\partial(\rho E A)_{2}}=u_{2}\left(1+\frac{\partial P}{\partial(\rho E)_{2}}\right) \\
\frac{\partial \operatorname{Res}}{\partial \dot{W}_{t}}=1
\end{gathered}
$$

The residual equation and the Jacobians are implemented into the RELAP-7 code in order to obtain solutions for the unknowns.

The pump head $H$ is calculated as

$$
H=\frac{\eta_{p} \dot{W}_{t}}{(\rho u A)_{1} g}
$$

where $g$ is the gravitational constant and $\eta_{p}$ is the pump efficiency.

The pump torque is calculated according to a scaling law as used in the Sandia model:

$$
\tau_{\text {pump }}=\frac{\tau_{p 0}}{\omega_{0}^{2}} \omega^{2}
$$

where $\tau_{p 0}$ and $\omega_{0}$ are the rated pump torque and speed, respectively.

Pressures at the inlet and outlet pipe ends are calculated with the incompressible flow Bernoulli equation. We assume that the pump work is added to the fluid only in the entrance segment and the loss in the exit segment is ignored. For normal flow

$$
\begin{gathered}
p_{1}=\left(p_{J}+\frac{1}{2} \rho_{J} u_{J}^{2}\right)-\rho_{1} g H-\frac{1}{2} \rho_{1} u_{1}^{2} \\
p_{2}=\left(p_{J}+\frac{1}{2} \rho_{J} u_{J}^{2}\right)-\frac{1}{2} \rho_{2} u_{2}^{2}
\end{gathered}
$$

where

$$
\begin{gathered}
\rho_{J}=\rho\left(p_{J}, T_{J}\right) \\
u_{J}=\frac{(\rho u A)_{1}}{\rho_{J} A_{J}}
\end{gathered}
$$

where $A_{J}$ is the pump reference cross section area.

Downstream total energy is calculated by

$$
(\rho E)_{2}=\rho_{2}\left(e\left(p_{J}, T_{J}\right)+\frac{1}{2} u_{2}^{2}\right)
$$

\subsection{Pump Homologous Curves}

The improved RCIC pump model described in subsection 2.2 would provide unique solutions to all the unknown variables in the nonlinear equation set. In this subsection, the homologous curves for the RCIC pump are implemented to further augment the RCIC pump model when the pump operating data are 
available.

Interaction of the pump and the fluid is described by empirically developed curves relating pump head and torque to the volumetric flow and pump angular velocity. Pump characteristic curves, frequently referred to as four-quadrant curves, present the information in terms of actual head $(H)$, torque $(\tau)$, volumetric flow rate $(\mathrm{Q})$, and angular velocity $(\omega)$. These data are generally available from pump manufacturers. For ease of code implementation, the four-quadrant curves are converted to a more condensed form, called homologous curves [6], which use dimensionless quantities. The dimensionless quantities involve the head ratio, torque ratio, volumetric flow ratio, and angular velocity ratio, where the ratios are actual values divided by rated values. The rated values are also required pump component input and correspond to the design point or point of maximum efficiency for the pump. The pump homologous data should be checked by computing pump efficiency from the homologous data. The non-dimensional homologous parameter are defined as: pump rotational speed ratio: $\alpha=\frac{\omega}{\omega_{R}}$, pump volumetric flow ratio: $v=\frac{Q}{Q_{R}}$, pump head ratio: $h=\frac{H}{H_{R}}$, pump torque ratio: $\beta=\frac{\tau}{\tau_{R}}$. The pump performance data are converted to homologous form with $\frac{h}{\alpha^{2}}, \frac{h}{v^{2}}, \frac{\beta}{\alpha^{2}}, \frac{\beta}{v^{2}}$ as the dependent variables and $\frac{v}{\alpha}, \frac{\alpha}{v}$ as the independent variables. The pump performance can be characterized with 8 input regimes or curves, as shown in the table below.

Table 1. Homologous Curves Regime Number

\begin{tabular}{|c|c|c|c|c|c|c|c|}
\hline $\begin{array}{l}\text { Regime } \\
\text { number }\end{array}$ & $\begin{array}{l}\text { Regime } \\
\text { mode } \\
\text { ID name }\end{array}$ & $\alpha$ & $\mathbf{v}$ & $\mathbf{v} / \alpha$ & $\begin{array}{c}\text { Independent } \\
\text { variable }^{\mathrm{a}}\end{array}$ & $\begin{array}{c}\text { Dependent }^{\mathrm{a}} \\
\text { variable } \\
\text { head }\end{array}$ & $\begin{array}{c}\text { Dependent }^{\mathrm{a}} \\
\text { variable } \\
\text { torque }\end{array}$ \\
\hline 1 & $\begin{array}{c}\text { HAN BAN } \\
\text { Normal } \\
\text { pump }\end{array}$ & $>0$ & $\geq 0$ & $\leq 1$ & $v / \alpha$ & $h / \alpha^{2}$ & $\beta / \alpha^{2}$ \\
\hline 2 & $\begin{array}{c}\text { HVN BVN } \\
\text { Normal } \\
\text { pump }\end{array}$ & $\geq 0$ & $\geq 0$ & $>1$ & $\alpha / v$ & $h / v^{2}$ & $\beta / v^{2}$ \\
\hline 3 & $\begin{array}{c}\text { HAD BAD } \\
\text { Energy } \\
\text { dissipation }\end{array}$ & $>0$ & $<0$ & $\geq-1$ & $v / \alpha$ & $h / \alpha^{2}$ & $\beta / \alpha^{2}$ \\
\hline 4 & $\begin{array}{l}\text { HVD BVD } \\
\text { Energy } \\
\text { dissipation }\end{array}$ & $\geq 0$ & $<0$ & $<-1$ & $\alpha / v$ & $\mathrm{~h} / \mathrm{v}^{2}$ & $\beta / v^{2}$ \\
\hline 5 & $\begin{array}{l}\text { HAT BAT } \\
\text { Normal } \\
\text { turbine }\end{array}$ & $<0$ & $\leq 0$ & $\leq 1$ & $v / \alpha$ & $h / \alpha^{2}$ & $\beta / \alpha^{2}$ \\
\hline 6 & $\begin{array}{c}\text { HVT BVT } \\
\text { Normal } \\
\text { turbine }\end{array}$ & $<0$ & $\leq 0$ & $>1$ & $\alpha / v$ & $h / v^{2}$ & $\beta / v^{2}$ \\
\hline 7 & $\begin{array}{c}\text { HAR BAR } \\
\text { Reverse } \\
\text { pump }\end{array}$ & $<0$ & $>0$ & $\geq-1$ & $\mathrm{v} / \alpha$ & $h / \alpha^{2}$ & $\beta / \alpha^{2}$ \\
\hline 8 & $\begin{array}{l}\text { HVR BVR } \\
\text { Reverse } \\
\text { pump }\end{array}$ & $<0$ & $>0$ & $<-1$ & $\alpha / v$ & $\mathrm{~h} / \mathrm{v}^{2}$ & $\beta / v^{2}$ \\
\hline
\end{tabular}

a. $\alpha=$ rotational ratio; $v=$ volumetric flow ratio; $h=$ head ratio; and $\beta=$ torque ratio. Note: For the case $\alpha=0$ and $v=0$ in regime $2, h=0$ and $\beta=0$.

In this work, the Pump normal operating regime 1 which is represented by the regime mode HAN for the pump head curve (Curve 1) and BAN for pump torque curve (Curve 1), and the pump normal operating regime 2 which is represented by the regime mode HVN for the pump head curve (Curve 2) and BVN for pump torque curve (Curve 2) are implemented into the RELAP-7 code. 


\subsubsection{Pump Head Curve 1 - HAN Regime}

Pump Head Curve 1 (HAN regime): In the HAN regime the independent variable is $x=\frac{v}{\alpha} \leq 1.0$ and the dependent variable is $y=\frac{h}{\alpha^{2}}$. A simplified curve for the HAN regime based on Fig. 3-5.10 of the RELAP5-3D Code Manual Volume I [6] for the pump head is developed as:

$$
y=-0.3 x+1.3
$$

where $=\frac{h}{\alpha^{2}}$, and $x=\frac{v}{\alpha}$, hence the equation becomes

$$
\begin{aligned}
& \frac{h}{\alpha^{2}}=-0.3 \frac{v}{\alpha}+1.3 \\
& h=1.3 \alpha^{2}-0.3 v \alpha
\end{aligned}
$$

since $h=H / H_{R}, \alpha=\omega / \omega_{R}, v=Q / Q_{R}$, the residual can be written as:

$$
\text { Res }=H-1.3\left(\frac{\omega}{\omega_{R}}\right)^{2} H_{R}+0.3 \frac{Q}{Q_{R}} \frac{\omega}{\omega_{R}} H_{R}
$$

The Jacobians are the following:

$$
\begin{gathered}
\operatorname{kee}(0,0)=\frac{\partial \operatorname{Res}}{\partial H}=1 \\
\frac{\partial R e s}{\partial \omega}=-2.6 \frac{\omega}{\omega_{R}} \frac{1}{\omega_{R}} H_{R}+0.3 \frac{Q}{Q_{R}} \frac{1}{\omega_{R}} H_{R} \\
\frac{\partial \operatorname{Res}}{\partial Q}=0.3 \frac{\omega}{\omega_{R}} \frac{1}{Q_{R}} H_{R} \\
\frac{\partial \operatorname{Res}}{\partial(\rho A)}=-\frac{(\rho u A) A}{(\rho A)^{2}} \frac{\partial \operatorname{Res}}{\partial Q} \\
\frac{\partial \operatorname{Res}}{\partial(\rho u A)}=\frac{A}{\rho A} \frac{\partial \operatorname{Res}}{\partial Q}
\end{gathered}
$$

\subsubsection{Pump Head Curve 2 - HVN Regime}

A simplified curve for the HVN regime based on Fig. 3-5.10 of the RELAP5-3D Code Manual Volume I [6] for the pump head is developed as:

$$
y=1.67(x-0.4)
$$

where $=\frac{h}{v^{2}}$, and $x=\frac{\alpha}{v}$, hence the equation becomes 


$$
\begin{gathered}
\frac{h}{v^{2}}=1.67\left(\frac{\alpha}{v}-0.4\right) \\
h=1.67 \alpha v-0.668 v^{2}
\end{gathered}
$$

since $h=H / H_{R}, \alpha=\omega / \omega_{R}, v=Q / Q_{R}$, the residual can be written as:

$$
\text { Res }=H-1.67 \frac{Q}{Q_{R}} \frac{\omega}{\omega_{R}} H_{R}+0.668\left(\frac{Q}{Q_{R}}\right)^{2} H_{R}
$$

The Jacobians are the following:

$$
\begin{gathered}
\text { kee }(0,0)=\frac{\partial \operatorname{Res}}{\partial H}=1 \\
\frac{\partial \operatorname{Res}}{\partial \omega}=-1.67 \frac{Q}{Q_{R}} \frac{1}{\omega_{R}} H_{R} \\
\frac{\partial \operatorname{Res}}{\partial Q}=-1.67 \frac{\omega}{\omega_{R}} \frac{1}{Q_{R}} H_{R}+1.336 \frac{Q}{Q_{R}} \frac{1}{Q_{R}} H_{R} \\
\frac{\partial \operatorname{Res}}{\partial(\rho A)}=-\frac{(\rho u A) A}{(\rho A)^{2}} \frac{\partial \operatorname{Res}}{\partial Q} \\
\frac{\partial \operatorname{Res}}{\partial(\rho u A)}=\frac{A}{\rho A} \frac{\partial \operatorname{Res}}{\partial Q}
\end{gathered}
$$

\subsubsection{Pump Torque Curve 1 - BAN Regime}

The Pump Torque Curve 1 (BAN regime) is developed based on Fig. 3.5-11 of the RELAP5-3D Code Manual Volume I [6] as:

$$
y=0.5 x+0.5
$$

where $=\frac{\beta}{\alpha^{2}}$, and $x=\frac{v}{\alpha}$, hence the equation becomes

$$
\frac{\beta}{\alpha^{2}}=0.5 \frac{v}{\alpha}+0.5
$$

since $\beta=\tau / \tau_{R}, \alpha=\omega / \omega_{R}, v=Q / Q_{R}$, then the equation can be written as:

$$
\beta=0.5 v \alpha+0.5 \alpha^{2}
$$

The residual is written as:

$$
\text { Res }=\frac{\tau}{\tau_{R}}-0.5 \frac{Q}{Q_{R}} \frac{\omega}{\omega_{R}}-0.5\left(\frac{\omega}{\omega_{R}}\right)^{2}
$$


The Jacobians are the following:

$$
\begin{gathered}
\text { kee }(0,0)=\frac{\partial \operatorname{Res}}{\partial \tau}=\frac{1}{\tau_{R}} \\
\frac{\partial R e s}{\partial \omega}=-0.5 \frac{Q}{Q_{R}} \frac{1}{\omega_{R}}-\frac{\omega}{\omega_{R}} \frac{1}{\omega_{R}} \\
\frac{\partial \operatorname{Res}}{\partial Q}=-0.5 \frac{\omega}{\omega_{R}} \frac{1}{Q_{R}} \\
\frac{\partial \operatorname{Res}}{\partial(\rho A)}=-\frac{(\rho u A) A}{(\rho A)^{2}} \frac{\partial \operatorname{Res}}{\partial Q} \\
\frac{\partial \operatorname{Res}}{\partial(\rho u A)}=\frac{A}{\rho A} \frac{\partial \operatorname{Res}}{\partial Q}
\end{gathered}
$$

\subsubsection{Pump Torque Curve 2 - BVN Regime}

A simplified curve for the BVN regime based on Fig. 3-5.11 of the RELAP5-3D Code Manual Volume I [6] for the pump torque is developed as:

$$
y=1.25(x-0.3)
$$

where $=\frac{\beta}{v^{2}}$, and $x=\frac{\alpha}{v}$, hence the above equation becomes

$$
\begin{gathered}
\frac{\beta}{v^{2}}=1.25\left(\frac{\alpha}{v}-0.3\right) \\
\beta=1.25 \alpha v-0.375 v^{2}
\end{gathered}
$$

since $\beta=\tau / \tau_{R}, \alpha=\omega / \omega_{R}, v=Q / Q_{R}$, then the equation can be written as:

$$
\frac{\tau}{\tau_{R}}=1.25 \frac{\omega}{\omega_{R}} \frac{Q}{Q_{R}}-0.375\left(\frac{Q}{Q_{R}}\right)^{2}
$$

The residual is written as:

$$
\text { Res }=\frac{\tau}{\tau_{R}}-1.25 \frac{\omega}{\omega_{R}} \frac{Q}{Q_{R}}+0.375\left(\frac{Q}{Q_{R}}\right)^{2}
$$

The Jacobians are the following:

$$
k e e(0,0)=\frac{\partial \operatorname{Res}}{\partial \tau}=\frac{1}{\tau_{R}}
$$




$$
\begin{gathered}
\frac{\partial R e s}{\partial \omega}=-1.25 \frac{Q}{Q_{R}} \frac{1}{\omega_{R}} \\
\frac{\partial R e s}{\partial Q}=-1.25 \frac{\omega}{\omega_{R}} \frac{1}{Q_{R}}+0.75 \frac{Q}{Q_{R}} \\
\frac{\partial \operatorname{Res}}{\partial(\rho A)}=-\frac{(\rho u A) A}{(\rho A)^{2}} \frac{\partial \operatorname{Res}}{\partial Q} \\
\frac{\partial \operatorname{Res}}{\partial(\rho u A)}=\frac{A}{\rho A} \frac{\partial \operatorname{Res}}{\partial Q}
\end{gathered}
$$

\subsection{Summary of Improved RCIC Pump Model with Homologous Curves}

The following is a summary of the improved RCIC pump model with the homologous curves. Four scalar variables: pump density $\rho$, pump energy $\rho e$, pump head $H$, and pump torque $\tau_{\text {pump }}$ are defined as the unknowns for the pump model. The turbine rotational speed $\omega$ and the turbine shaft work $\dot{W}_{t}$ are the two unknowns for the Terry turbine rotor model.

\subsubsection{Homologous Curves 1 - HAN/BAN Regimes}

$$
\begin{gathered}
I \frac{d \omega}{d t}+\frac{\tau_{\text {pump }}}{1+\cos \beta}=c_{I C}\left(2 r \dot{m} V_{j} \frac{\cos \beta}{1+\cos \beta}-r^{2} \dot{m} \omega\right) \\
\dot{W}_{t}=\tau_{\text {pump }} \omega \\
V \frac{\partial \rho}{\partial t}=(\rho u A)_{1}-(\rho u A)_{2} \\
V \frac{\partial(\rho e)}{\partial t}=\left(E+\frac{p}{\rho}\right)_{1}(\rho u A)_{1}+\dot{W}_{t}-\left(E+\frac{p}{\rho}\right)_{2}(\rho u A)_{2} \\
H=1.3\left(\frac{\omega}{\omega_{R}}\right)^{2} H_{R}-0.3 \frac{Q}{Q_{R}} \frac{\omega}{\omega_{R}} H_{R} \\
\tau=0.5 \frac{Q}{Q_{R}} \frac{\omega}{\omega_{R}} \tau_{R}+0.5\left(\frac{\omega}{\omega_{R}}\right)^{2} \tau_{R}
\end{gathered}
$$

\subsubsection{Homologous Curves 2 - HVN/BVN Regimes}

$$
\begin{gathered}
I \frac{d \omega}{d t}+\frac{\tau_{\text {pump }}}{1+\cos \beta}=c_{I C}\left(2 r \dot{m} V_{j} \frac{\cos \beta}{1+\cos \beta}-r^{2} \dot{m} \omega\right) \\
\dot{W}_{t}=\tau_{\text {pump }} \omega \\
V \frac{\partial \rho}{\partial t}=(\rho u A)_{1}-(\rho u A)_{2} \\
V \frac{\partial(\rho e)}{\partial t}=\left(E+\frac{p}{\rho}\right)_{1}(\rho u A)_{1}+\dot{W}_{t}-\left(E+\frac{p}{\rho}\right)_{2}(\rho u A)_{2}
\end{gathered}
$$




$$
\begin{gathered}
H=1.67 \frac{Q}{Q_{R}} \frac{\omega}{\omega_{R}} H_{R}-0.668\left(\frac{Q}{Q_{R}}\right)^{2} H_{R} \\
\tau=1.25 \frac{\omega}{\omega_{R}} \frac{Q}{Q_{R}} \tau_{R}-0.375\left(\frac{Q}{Q_{R}}\right)^{2} \tau_{R}
\end{gathered}
$$




\section{IMPROVED RCIC PUMP MODEL TESTS WITH HOMOLOGOUS CURVES}

\subsection{Improved RCIC Pump Model Start-up Tests with Homologous Curves}

The same RELAP-7 input model used for testing the single-phase and two-phase Terry turbine model as shown in Figure 2 in the previous work $[4,5]$ was used to test the improved RCIC pump model with homologous curves. The input model is composed of a Terry turbine model, a coupled pump, a check valve on the water line, connecting pipes and time-dependent volumes at the boundaries. The boundary conditions are also shown in the figure. Two different turbine outlet pressures at $193 \mathrm{kPa}$ and $300 \mathrm{kPa}$ as used for the Terry turbine nozzle test are used in these simulations. The two-phase model simulation results are compared to the nominal steady-state values and single-phase results.

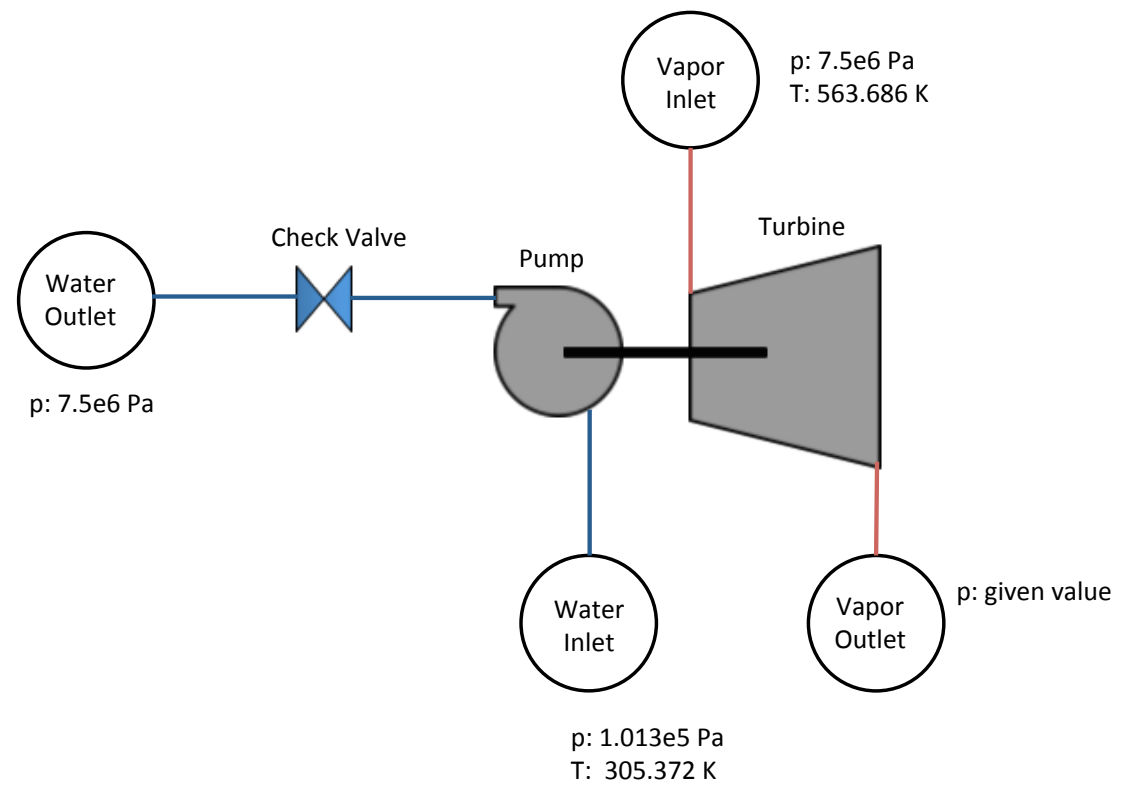

Figure 2. RELAP-7 Terry turbine RCIC system test model.

Table 1 shows the major parameters for the turbine and pump. These values are taken from the Sandia MELCOR test case which is based on a RCIC system for a generic 2000 MWt BWR [1].

The simulation was run for $100 \mathrm{~s}$ to reach steady state. The time step in the beginning is $0.001 \mathrm{~s}$, and gradually increases to $0.01 \mathrm{~s}$ at $10 \mathrm{~s}$ and maintains this value. The nozzle parameters rapidly achieve steady state values. Other major parameters of interest such as the shaft work, rotational speed, and pump torque take more than 1 minute to reach steady state. Table 2 and Table 3 compare important steady-state results from the improved two-phase models, single-phase model, Sandia model, and rated nominal values for the turbine outlet pressures at $193 \mathrm{kPa}$ and $350 \mathrm{kPa}$, respectively. All model results are quite close to the rated values. The two-phase model with Moody's choking model produces closer results to the single-phase model than the IHEM choking model. Comparing results between two different outletpressure conditions, a higher outlet pressure results in a slower shaft speed, less torque, less shaft work, and a smaller pump mass flow rate for all the models; but the difference is not large. The calculated RCIC rotational speed at steady state from the Moody model is 446 radians/s, which is very close to the rated speed of 450 radians/s shown in Table 2 . The calculated pump torque at steady state from the Moody 
model is $436 \mathrm{~N}-\mathrm{m}$, again very close to the rated value of $449 \mathrm{~N}-\mathrm{m}$. The calculated steady-state shaft work from the Moody model is very close to the rated value: $194 \mathrm{~kW}$ versus $202 \mathrm{~kW}$ (450 radians/s × $449 \mathrm{~N}$ $\mathrm{m})$. The mass flow rate through the pump is about 10 times that of the turbine at steady state, which is the expected ratio for a typical RCIC system. The steam quality at the nozzle exit from both two-phase models is about 0.92 .

Table 2. Terry turbine and pump parameters

\begin{tabular}{|l|c|}
\hline \multicolumn{1}{|c|}{ Model Parameters } & Value \\
\hline Turbine wheel radius $(\mathrm{r})$ & $0.3 \mathrm{~m}$ \\
\hline Turbine inlet/outlet angle $(\beta)$ & $\pi / 4$ radians \\
\hline Number of nozzles & 5 \\
\hline Total nozzle throat area & $1.2315 \mathrm{e}-4 \mathrm{~m}^{2}$ \\
\hline Total nozzle exit area & $2.048 \mathrm{e}-4 \mathrm{~m}^{2}$ \\
\hline Turbine moment of inertia $(\mathrm{I})$ & $10 \mathrm{~kg}-\mathrm{m}^{2}$ \\
\hline Impulse conversion coefficient $\left(\mathrm{c}_{\mathrm{IC}}\right)$ & 1.1 \\
\hline Rated RCIC speed $\left(\omega_{0}\right)$ & $450.295 \mathrm{radians} / \mathrm{s}(4300 \mathrm{rpm})$ \\
\hline Rated pump torque $\left(T_{p 0}\right)$ & $449 \mathrm{~N}-\mathrm{m}$ \\
\hline Rated volumetric flow rate & $0.014 \mathrm{~m} / \mathrm{s}$ \\
\hline Rated pump head & $766 \mathrm{~m}(7.52 \mathrm{MPa})$ \\
\hline
\end{tabular}


Table 3. Important Terry turbine and pump calculated parameters at steady state for outlet pressure at 193 $\mathrm{kPa}$

\begin{tabular}{|c|c|c|c|c|c|}
\hline Model Parameters & $\begin{array}{l}\text { Rated } \\
\text { Value }\end{array}$ & $\begin{array}{l}\text { Modified } \\
\text { Sandia } \\
\text { Model }\end{array}$ & $\begin{array}{c}\text { INL Model } \\
\text { (Pure } \\
\text { Steam) }\end{array}$ & $\begin{array}{c}\text { Improved INL } \\
\text { Model with } \\
\text { Homologous } \\
\text { Curves } \\
\text { (IHEM) }\end{array}$ & $\begin{array}{c}\text { Improved INL } \\
\text { Model with } \\
\text { Homologous } \\
\text { Curves } \\
\text { (Moody) }\end{array}$ \\
\hline Pump efficiency & N/A & 0.49 & 0.52 & 0.514 & 0.518 \\
\hline $\begin{array}{l}\text { Turbine impulse } \\
\text { conversion } \\
\text { coefficient }\end{array}$ & N/A & N/A & 0.98 & 1.1 & 1.1 \\
\hline Pump head, $\mathrm{m}$ & 766. & 755. & 755. & 755. & 755. \\
\hline RCIC speed, $\mathrm{rad} / \mathrm{s}$ & 450. & 455. & 446. & 444. & 446. \\
\hline Pump torque, N-m & 449. & 459. & 441. & 424. & 436. \\
\hline Shaft work, kW & 202. & 209. & 197. & 188. & 194. \\
\hline $\begin{array}{l}\text { Bucket entrance } \\
\text { speed, } \mathrm{m} / \mathrm{s}\end{array}$ & N/A & 946. & 928. & 908. & 907. \\
\hline $\begin{array}{l}\text { Turbine mass flow } \\
\text { rate, } \mathrm{kg} / \mathrm{s}\end{array}$ & N/A & 1.39 & 1.39 & 1.32 & 1.36 \\
\hline $\begin{array}{l}\text { Pump mass flow } \\
\text { rate, } \mathrm{kg} / \mathrm{s}\end{array}$ & $\mathrm{N} / \mathrm{A}$ & 13.83 & 13.84 & 13.07 & 13.61 \\
\hline
\end{tabular}


Table 4. Important Terry turbine and pump calculated parameters at steady state for outlet pressure at 300 $\mathrm{kPa}$

\begin{tabular}{|c|c|c|c|c|c|}
\hline Model Parameters & $\begin{array}{l}\text { Rated } \\
\text { Value }\end{array}$ & $\begin{array}{c}\text { Modified } \\
\text { Sandia } \\
\text { Model }\end{array}$ & $\begin{array}{c}\text { INL Model } \\
\text { (Pure } \\
\text { Steam) }\end{array}$ & $\begin{array}{l}\text { Improved INL } \\
\text { Model with } \\
\text { Homologous } \\
\text { Curves } \\
\text { (IHEM) }\end{array}$ & $\begin{array}{l}\text { Improved INL } \\
\text { Model with } \\
\text { Homologous } \\
\text { Curves } \\
\text { (Moody) }\end{array}$ \\
\hline Pump efficiency & N/A & 0.49 & 0.52 & 0.509 & 0.513 \\
\hline $\begin{array}{l}\text { Turbine impulse } \\
\text { conversion } \\
\text { coefficient }\end{array}$ & N/A & N/A & 0.98 & 1.1 & 1.1 \\
\hline Pump head, $\mathrm{m}$ & 766. & 755. & 755. & 755. & 755. \\
\hline RCIC speed, rad/s & 450. & 427. & 442. & 441. & 443. \\
\hline Pump torque, N-m & 449. & 403. & 433. & 411. & 422. \\
\hline Shaft work, kW & 202. & 172. & 192. & 181. & 187. \\
\hline $\begin{array}{l}\text { Bucket entrance } \\
\text { speed, } \mathrm{m} / \mathrm{s}\end{array}$ & N/A & 841. & 913. & 883. & 882. \\
\hline $\begin{array}{l}\text { Turbine mass flow } \\
\text { rate, } \mathrm{kg} / \mathrm{s}\end{array}$ & N/A & 1.39 & 1.39 & 1.32 & 1.36 \\
\hline $\begin{array}{l}\text { Pump mass flow } \\
\text { rate, } \mathrm{kg} / \mathrm{s}\end{array}$ & $\mathrm{N} / \mathrm{A}$ & 11.39 & 13.47 & 12.44 & 12.95 \\
\hline
\end{tabular}

\subsection{RCIC System Test with Periodic Inlet Boundary Conditions}

A RCIC system test with a periodic steam quality inlet condition has been developed based on the model shown in Figure 3 in order to test the two-phase Terry turbine model. The turbine inlet pressure is 7.5 $\mathrm{MPa}$ and the turbine outlet pressure is $193 \mathrm{kPa}$. The steam quality at the turbine inlet as shown in Figure 3 is inputted through a control file. The goal is to create a Fukushima-accident-like scenario, with reasonable self-regulating behavior appearing in the simulation. Only the Moody two-phase model is used. The simulation covers about two cycles of dry steam and low-quality two-phase flow stages. A quick transition period of 20 seconds is assumed between the dry steam turbine inlet and the low-quality (0.1) two-phase flow turbine inlet conditions.

Figure 4 shows the mass flow rates through the RCIC system, i.e. the pumped water mass flow rate, the turbine mixture mass flow rate and the turbine steam mass flow rate. Figure 5 shows the 
calculated RCIC turbine shaft work. Figure 6 shows the calculated RCIC pump efficiency with periodic inlet condition.

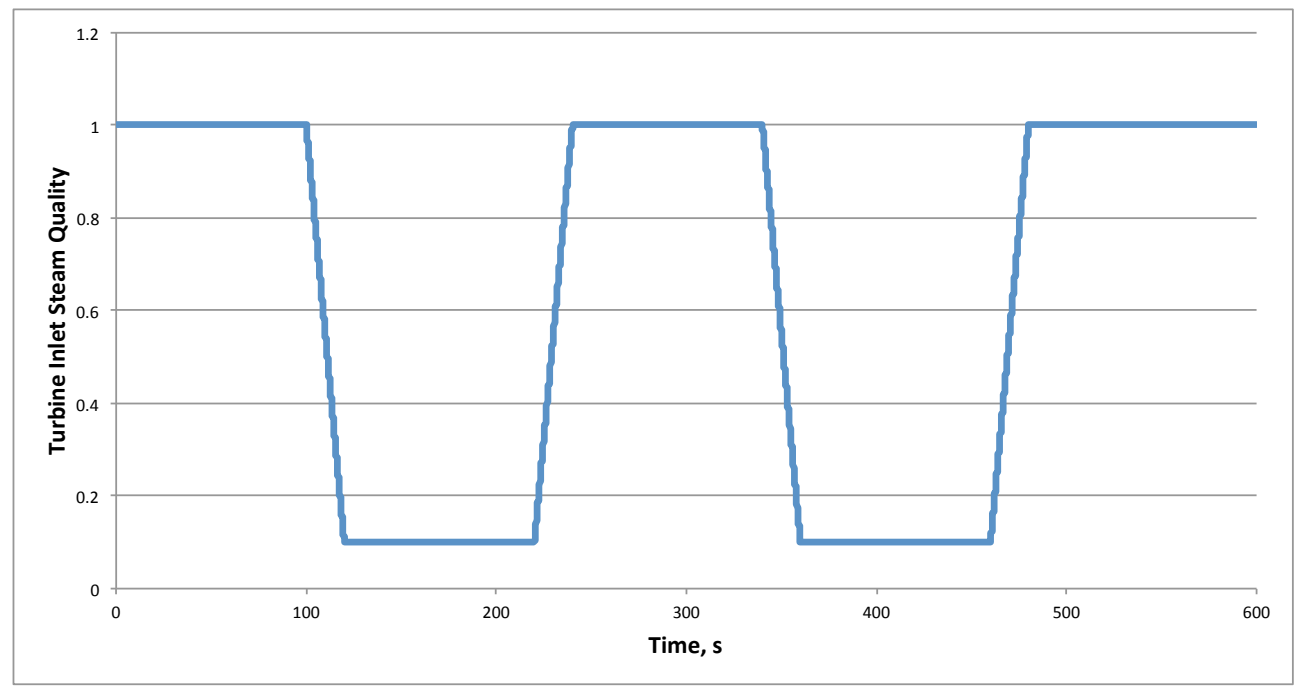

Figure 3. Specified turbine inlet steam quality for the RCIC system simulation with periodic inlet condition.

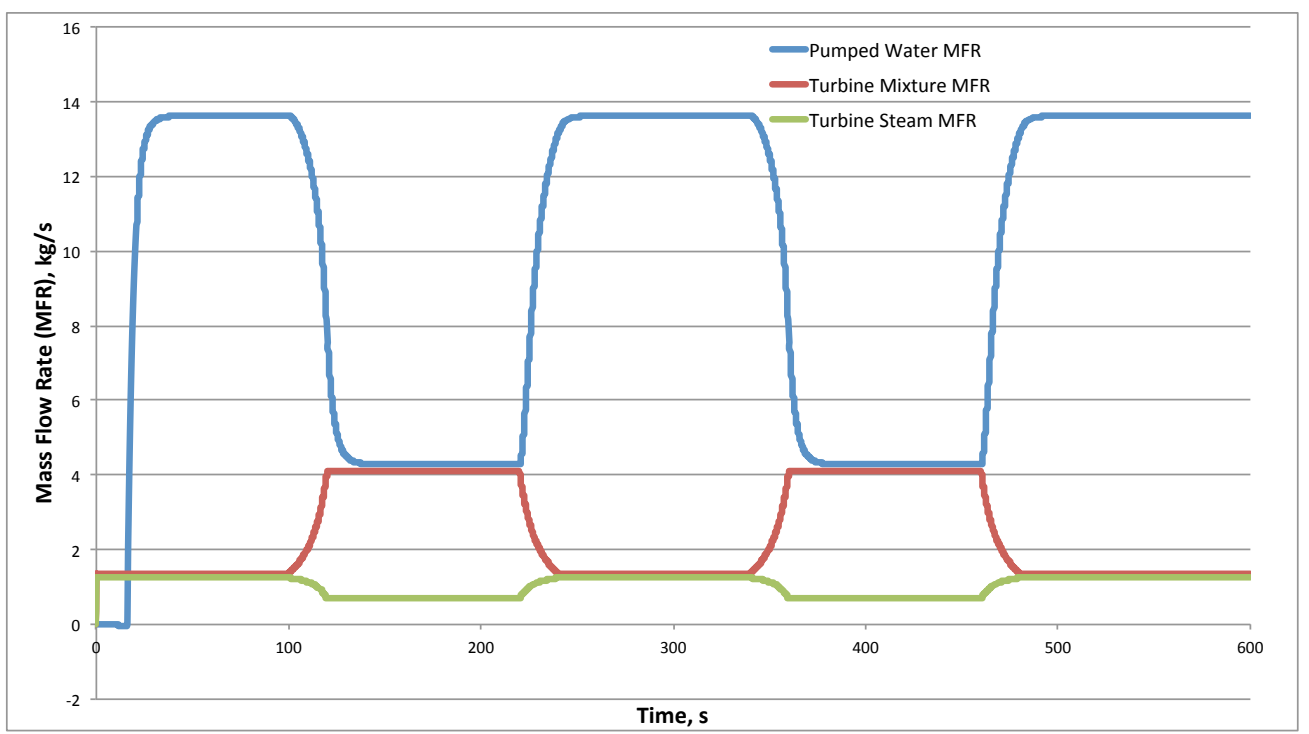

Figure 4. Calculated mass flow rates through the RCIC turbopump - mixture and steam through the turbine nozzle exit, water through the pump for the RCIC system simulation with periodic inlet condition and the Moody model. 


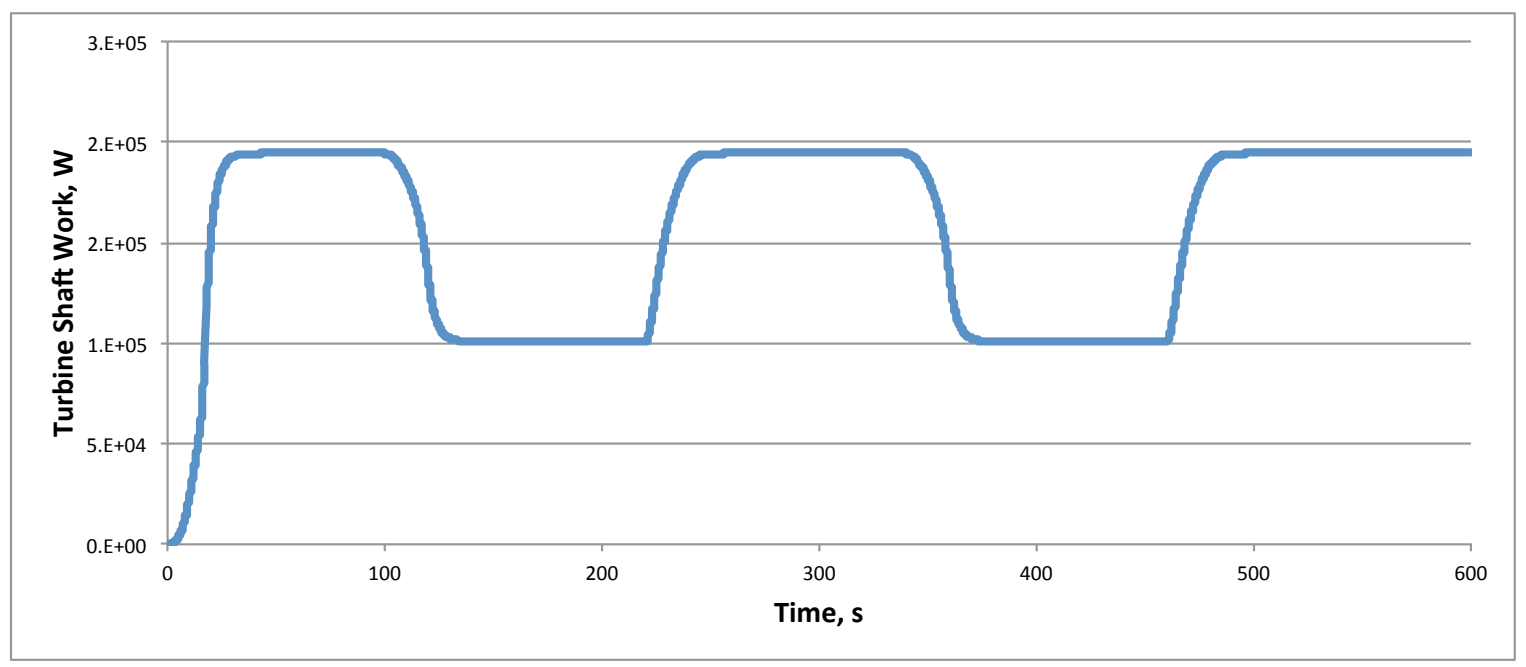

Figure 5. Calculated turbine shaft work for the RCIC system simulation with periodic inlet condition.

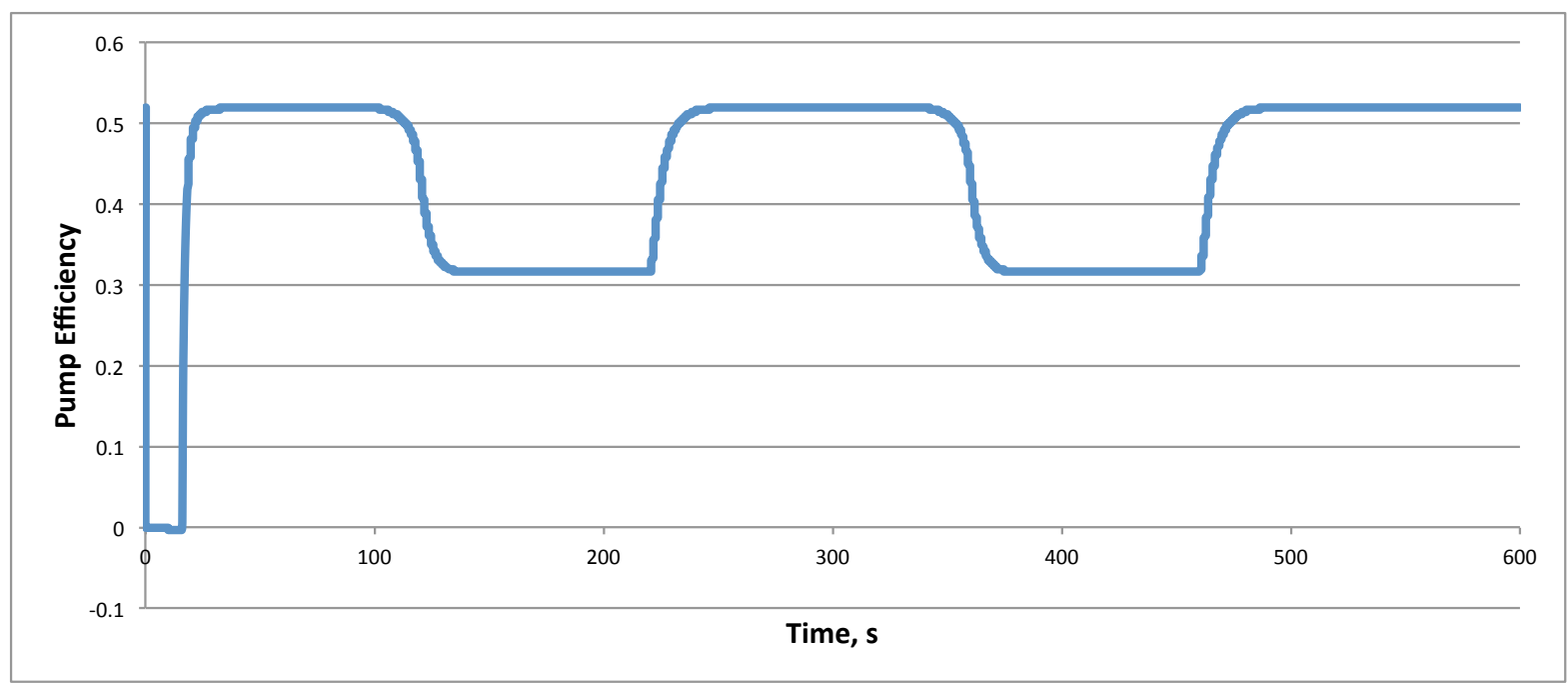

Figure 6. Calculated RCIC pump efficiency for the RCIC system simulation with periodic inlet condition and the Moody model. 


\section{SUMMARY}

In this work, we present an improved INL RCIC Pump model which allows the nonlinear equation system to be adequately constrained such that unique solutions to the unknown variables can be found. The HAN and HVN regimes of the pump head homologous curves and the BAN and BVN regimes of the pump torque homologous curves under the pump normal operating conditions are also implemented into the RELAP-7 code along with the improved INL RCIC Pump model. The improved INL RCIC Pump model and the homologous curves have been tested with the RCIC start-up tests. Two-phase models were also simulated and compared with the single-phase model. Similar results are obtained. Finally, we designed a RCIC system test case to simulate the self-regulated Terry turbine behavior that was observed in the Fukushima accidents. In this test, a periodic inlet condition for steam quality varying from 1 to 0.1 was applied. For the dry-steam inlet period, the RCIC system behaves just like the normal operating condition, with a high pump injection flow rate and a nominal steam release rate through the turbine, resulting in the net addition of water to the primary system; for the off-normal low-quality two-phase flow inlet period, the RCIC turbine shaft work dramatically decreases resulting in a much reduced pump injection flow rate and an increased mixture flow rate out of the turbine.

This work represents the first step for two-phase Terry turbine analytical models. These preliminary models can be refined with more local modeling choices. The near future work should be focused on using Terry turbine test data to validate the proposed models when the data become available. Additional model refinement will also be pursued, such as trying additional choking models and investigating different nozzle expansion models in the nozzle divergent section. Thermal mixing and stratification models should also be developed for the wet well. 


\section{REFERENCES}

1. K. Ross, et. al., Modeling of the Reactor Core Isolation Cooling Response to Beyond Design Basis Operations - Phase 1, SAND2015-10662, December, 2015.

2. R. Gauntt, et. al., "Fukushima Daiichi Accident Study (Status as of April 2012)," SAND20126173, Sandia National Laboratories, Albuquerque, NM, August 2012.

3. R.T. Lahey, Jr. and F.J. Moody, The thermal-Hydraulics of A Boiling Water Nuclear Reactor, $2^{\text {nd }}$ edition, American Nuclear Society, 1993.

4. H. Zhao, et. al., Development and Implementation of Mechanistic Terry Turbine Models in RELAP-7 to Simulate RCIC Normal Operation Conditions, INL/EXT-16-39857, rev 1, January 2017.

5. H. Zhao and J. O'Brien, Preliminary Two-Phase Terry Turbine Nozzle Models for RCIC OffDesign Operation Conditions, INL/EXT-17-42125, June 2017.

6. RELAP5-3DC Code Manual Volume I: Code Structure, System Models and Solution Methods, INL/MIS-15-36723 Revision 4.3 October 2015. 